Ihre Fragen zur Abrechnung und zur wirtschaftlichen Praxisführung beantwortet unser Experte Helmut Walbert, Würzburg.

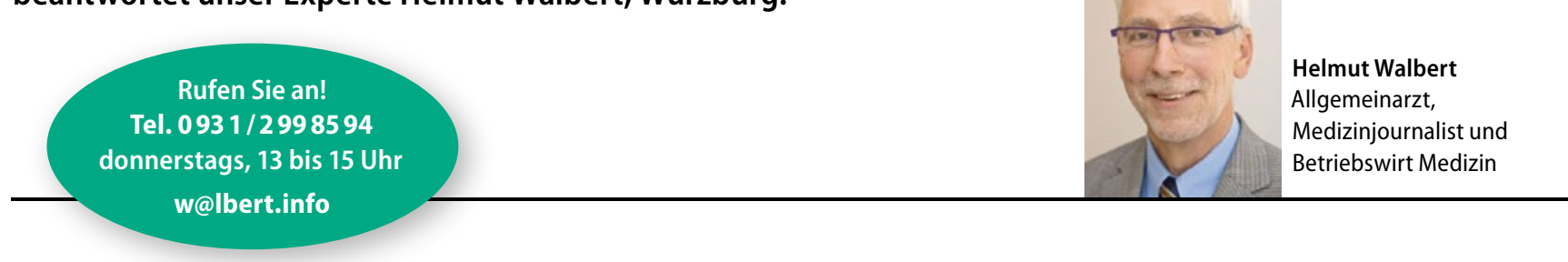

\title{
BZ-Messgerät nach Wunsch verordnen
}

$?$ Dr. A. W. Allgemeinarzt, Nordrhein: Ich darf nach Aussage der Landesärztekammer aus wettbewerbsund berufsrechtlichen Gründen keine Blutzuckermessgeräte mehr kostenfrei an Patienten abgeben. Wie gehe ich vor, wenn ich ein bestimmtes Messgerät verordnen will?

MMW-Experte Walbert: Grundsätzlich dürfen die Messgeräte nur bei insulinbehandelten, geschulten Diabetikern verordnet werden - oder bei einer Therapieumstellung mit Hypoglykämiegefahr, dann aber nur kurzfristig. Wir halten in der Praxis für diese seltenen Fälle ein Leihgerät vor, sodass nur die Kosten für die Teststreifen anfallen.

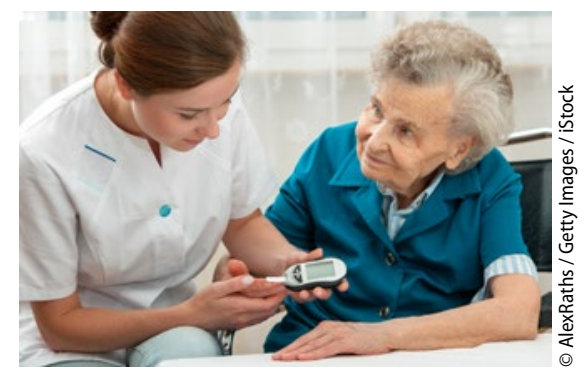

Das gewohnte Gerät kann nicht einfach an den Patienten abgegeben werden.

Im Hilfsmittelverzeichnis gibt es zwei zugelassene Positionen: 21.34.02.1, Blutzuckermessgeräte, und 21.34.02.2, Blutzuckermessgeräte mit Sprachausgabe. Eine dieser Positionen muss aufs Rezept.
Apotheke, Sanitätshaus oder Lieferant müssen dann gemäß dem Vertrag mit der jeweiligen Krankenkasse ein Gerät herausgeben. Will der Arzt ein bestimmtes Gerät, muss dies namentlich bezeichnet und das Aut-idem-Verbot angekreuzt werden. Bei der Auswahl der Geräte sollte der Arzt beachten, dass die zugehörigen Teststreifen in die Preisgruppen B und A2 gehören, weil sonst ein Regress droht.

Zusätzlich muss man in manchen KVen noch Quoten für die einzelnen Preisklassen der Teststreifen beachten. Ansonsten sind die Apotheker auch hier angehalten, auf billigere Teststreifen umzustellen - wenn der Arzt dies nicht per Aut-idem-Kreuz verbietet.

\section{Paravertebrale Inflitration in der GOÄ}

? Dr. H. G., Allgemeinarzt, Bayern: Patienten mit akutem Wirbelsäulensyndrom bieten wir in unserer Praxis eine paravertebrale Infiltration an. Die Behandlung hat sich in den meisten Fällen als wirkungsvoll und sicher erwiesen. Es stellt sich jedoch die Frage, wie wir das bei Selbstzahlern nach GOÄ abrechnen sollen? Möglich wären meiner Ansicht nach die Nrn. 255 und 267. Sehe ich das richtig, oder gibt es noch andere Möglichkeiten?

MMW-Experte Walbert: Die Nr. 267 ist hier auf jeden Fall möglich, da die Leistung ja in der Beschreibung ex-

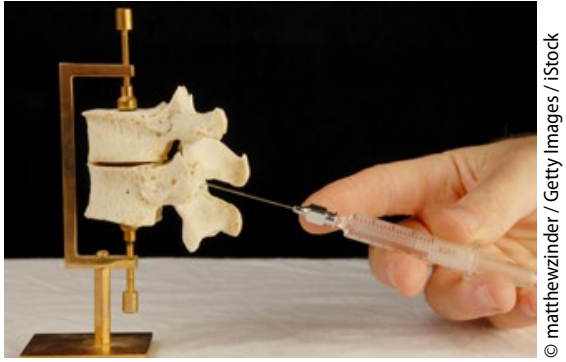

Eine solche Facettengelenksinfiltration kann Schmerzen reduzieren.

plizit aufgeführt wird: „Medikamentöse Infiltrationsbehandlung im Bereich einer Körperregion, auch paravertebrale oder perineurale oder perikapsuläre oder retrobulbäre Injektion und/oder Infiltration". Hier können je Sitzung 4,66 Euro abgerechnet werden.

Aus wirtschaftlichen Überlegungen sollte aber stets die höchstbewerte $\mathrm{Nr}$ gewählt werden, deren Leistungsinhalt erfüllt wurde. In diesem Fall wäre also die Nr. 255 für eine „Injektion, intraartikulär oder perineural" vorzuziehen, da sie mit 5,54 Euro bewertet ist.

Theoretisch käme auch noch eine weitere Position infrage, nämlich die $\mathrm{Nr}$. 490, „Infiltrationsanästhesie kleiner Bezirke“. Sie ist allerdings nur mit 3,56 Euro bewertet. 